\title{
Selected Problems of the Environmental Impact Analysis of Investment Projects Based on Life Cycle Assessment Procedure
}

\author{
Elżbieta Szafranko' \\ 1 University of Warmia and Mazury in Olsztyn, Faculty of Geodesy, Geospatial and Civil Engineering, \\ ul. Heweliusza4, 10-724 Olsztyn, Poland \\ e-mail: elasz@uwm.edu.pl
}

\begin{abstract}
The building objects show a wide variety. Among them, we can distinguish buildings and various building constructions. In addition to the fact that they are of various sizes, they perform different functions, while their purpose and use generates various problems, they can be made using various materials, different technologies and construction solutions. Therefore, the decision on which solutions to apply may be difficult to make. In this situation, it is good to develop several alternative solutions for their comprehensive comparison. In addition, the existing regulations that originate in the EU directives, in many cases impose the obligation to develop several variants of future investments and analyze them taking into account many factors. In the EU recommendations, the analysis related to the impact of construction investments on the environment is of highest importance. The ISO 14040-1404X regulations created and introduced by the European Union are the most important tool for a global assessment of the environmental impact of a product, facility and service. They relate to the environmental impact assessment of the entire Life Cycle Assessment (LCA), and their assumption is to identify and minimize any environmental impacts that may arise from the production, use and disposal of the product. Research should include specific stages according to the LCA evaluation system: determination of the purpose and scope of the assessment, inventory of input and output data and the impact assessment. The following research methods were used: source materials analysis, library query, advanced data collection methods through online surveys, LCA assessment, multicriterial methods. The research conducted by the author showed that the analysis involving selected problems related to the object-environment interaction is dominant. However, in practice it is difficult to find the analyses covering the entire lifecycle of an object in accordance with the LCA procedure and examples of comparison of specific design solutions within the variant assessment procedure taking into account the LCA procedure. The aim of the article is to show how such procedure can look while comparing the exemplary variants of a construction project. The article presents an example and diagrams of conduct covering the whole life cycle of an object, and the analysis is based on specific examples.
\end{abstract}

Keywords: green technology, Life Cycle Assessment, assessment criteria, multicriteria methods

\section{INTRODUCTION}

The construction industry is among these branches of economy that have the heaviest impact on the environment. According to the European Commission, it consumes about $42 \%$ of the energy and emits $35 \%$ of greenhouse gases in the whole European Union. The consumption of building materials corresponds to over $50 \%$ of the total production in Europe, and concrete production globally uses up 20 billion tons of aggregates, 1.5 billion tons of cement and 800 billion tons of water. Beside the consumption of natural resources at the stage of their construction, buildings generate numerous loads to the environment during their useful life. Another important question is what happens to a building which is withdrawn from use. Thus, a building should be analyzed in the perspective of its complete life cycle: from the production of materials, construction work and useful life, to its demolition and recycling of the demolition waste. Experts distinguish two basic guidelines that enable us to relieve the environmental load: passing through the phases 
in a life cycle so as to minimize the absorbed resources, and minimizing consumption of resources and emission of pollutants at every stage of the building's life [1,2].

As the environmental conservation is a priority goal, new concepts of proecological behavior are being developed. These include green technologies. In the construction industry, green technologies mostly indicate effective management of energy and natural resources, from the manufacturing of materials and implementing energy-saving technologies, to the design solutions and technologies used during the construction work and, subsequently, during the useful life of a construction. Another important issue is how the demolition waste will be recovered and recycled. These actions should be viewed from the perspective of the entire life cycle of a building $[5,7]$.

\section{Concept of a life cycle of a building, (concept of LCA)}

In line with the EU directives, the life cycle of a building encompasses all phases of the existence of a delivered building commodity, service or job, especially: research, design, testing, production, transport, use, repairs, modernisation, refurbishment, and maintenance during the whole period of useful life, depreciation, demolition, and removal. The idea of a life cycle is fundamental to broader analyses that include the actions 'from concept to demolition', and serves as a base for a complex assessment of any building enterprise $[7,8]$. The structure of a life cycle is illustrated in Figure 1.
The complex approach to the life cycle of a building has given rise to various concepts of how to assess buildings. These include the Ecological (Environmental) Assessment of the Life Cycle LCA (Life Cycle Assessment). This approach is defined as 'the aggregation and evaluation of input and output data, and environmental influences of the system of a given product during its life cycle.' Inputs are quantitative and the qualitative data concerning resources as well as the energy consumed to carry out the analysed process. The outcomes of this process, i.e., both desired products and services, and emissions and waste, are the outputs of a process $[3,8]$. The product system is perceived as a set of unit processes, i.e. its smallest components, interconnected by sharing materials and energy supply. Every system has boundaries, which are set up by the system's designer, and an assessment can include different production processes or particular stages in a technological line. Hence, evaluation is composed of the following stages: identification of an assessment's goal and scope, analysis of a set of input data, assessment of the influences on the environment, and final interpretation. Figure 2 shows a schematic presentation of this process.

\section{Factors in an assessment of proecological solutions (green technology)}

An analysis which captures the whole life cycle of a building generates a series of factors, which can undergo subsequent evaluation $[4,5]$. They can be described and classified according to the division into the basic life cycle stages, enabling

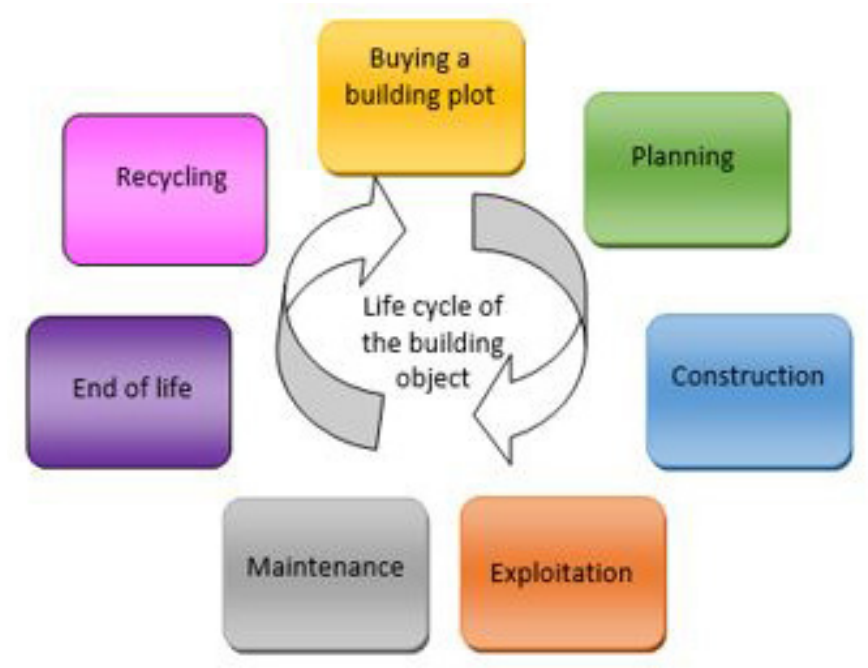

Figure 1. Diagram of live cycle for building construction 


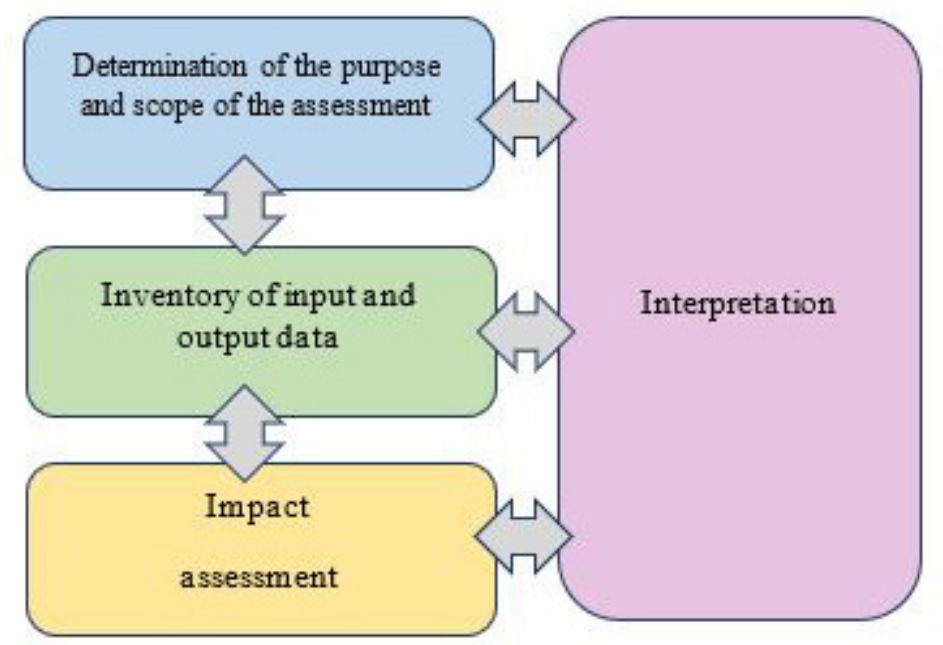

Figure 2. Evaluation system for LCA, source: the author, based on [3, 6]

to distinguish certain processes, e.g. preparation of building materials, construction of a building, using the finished building, demolition. The observations made during this study enabled the author to identify a number of factors which affect the ultimate outcome of an assessment. A list of the most important indicators which occur in LCA assessments is presented below [5].

\section{Ecological assessment of building materials and the process of their preparation}

As the construction industry is the branch of economy that probably consumes the most resources and raw material worldwide, it is significant to pay attention to the proper management of materials, optimisation of the manufacture of building materials and consumption of energy due to production and transport of the building materials [3, 7]. An ecological assessment of this stage includes the following criteria:

- resourceful use of natural raw materials - protection of fossil resources, use of renewable resources, use of recycled materials;

- elimination of hazardous chemical and biological contaminants - minimising the toxic emission to the environment, avoiding dangerous contamination in the event of a failure that could threaten human health or life; elimination of biological hazards during the production and use of building materials;

- optimising the energy consumption during the production process, transport and processing of building materials;

- saving the energy needed to heat a building by using materials which lower the energy demand of a building;
- assessment of the durability of material without it losing desired properties - long durability of materials, minimising the need for repairs;

- recovery of materials and recyclability - easy to disassemble or demolish, recyclable;

- minimising the amounts of waste under standard conditions - no need to set up special dumping sites, safe storage of waste.

As can be seen, several of the factors defined with respect to the manufacture of building materials are associated with the subsequent usage of these materials for constructing a building, and with their utilisation or possible recycling $[3,8]$.

\section{Assessment of a building process}

The process of constructing a building is the shortest phase in its life cycle. Its assessment can be summarized in a few points:

- resourceful use of space and protection of the natural surroundings of a building site;

- resourceful use of building materials;

- execution of the construction works inclusive of eco-friendly processes;

- implementation of energy-saving technologies;

- minimizing the transport of materials to a construction site.

\section{Assessment of the useful life of a building}

The time when a building or a building construction is used lasts the longest and comprises many aspects. Two groups of actions can be distinguished: normal use of a building including regular maintenance, and the necessary repairs and refurbishment to preserve the building's 
adequate technical condition. The following factors can be listed:

- reducing the emission of wastewater, sewage and other waste, and reducing energy consumption;

- using durable materials, limiting maintenance and repairs;

- using pro-ecological technologies during major repairs;

- using the existing buildings as long as possible, taking care of the existing buildings.

Assessment of the process of demolition, recyclability and utilisation of demolition waste

An assessment of the recyclability of demolition waste and possible problems of their recovery are often the most important contributor to an LCA evaluation. This problem has been given considerable attention in the EU regulations and directives. The most important guidelines originate from the following assessment factors:

- safe demolition of a building;

- selective collection of demolition waste, which enables their re-use;

- recovery of material and its recyclability easy disassembly or demolition;

- safe storage of waste, minimising amounts of waste, no need to set up special dumping sites.

The above-mentioned factors, related to the stages in the life cycle of a building, illustrate the diversity of problems considered during an LCA (Life Cycle Assessment) procedure. They can serve as the criteria for evaluating the variant designs of planned buildings.

Due to their large number, only some of these criteria are actually selected for an evaluation of a single case $[3,7,8]$.

\section{Selection of criteria, research methodology}

An assessment of variants of building investments typically relies on many factors. If an analysis is to comprise the whole life cycle of a building, the number of factors is greater $[10,11]$. Therefore, it is helpful to arrange the criteria into groups, i.e. the main criteria and subcriteria. A natural consequence of including all life cycle phases is to divide them $[11,12]$ into the following groups:

1. Factors connected with the preparation of building materials

2. Evaluation of the construction process
3. Evaluation of the useful life of a ready building 4. Evaluation of the process of demolition and recyclability of demolition waste.

The diagram presented in Figure 3 shows the hierarchy of main and subordinate criteria for an assessment of a building investment case. The factors presented in such a way enable one to apply a hierarchy analytical method and take the entire life cycle of a building into account.

The criteria identified previously can be applied in a complex assessment of any building. However, their application in further evaluations calls for the identification of their importance. On the basis of the opinions expressed by experts in a questionnaire, the most important criteria in an evaluation were determined. The importance of criteria was evaluated via a survey, where answers to a series of questions were given, e.g. 'Which element (criterion) is most important in your opinion in relation to the above problem?' The answers consisted of points assigned according to a given scale. For instance, a scale from 0 to 5 is interpreted as follows: 5 points mean the maximum satisfaction of the goal by the analysed factor, 0 - complete lack thereof. The relevant literature and other research carried out with the same method provide us with some examples $[5,8,11,12]$.

On the basis of these examples, the author developed templates of questionnaires used in research. The examples are given in Figure 4.

\section{Case study of an assessment of criteria covering the whole life cycle of an object - the author's own research}

In order to illustrate the research problem and an approach to the assessment of the importance of criteria, fragments of the calculations which correspond to the specification of weights obtained from surveys before and after their processing for further calculations are shown below. The specification comprises criteria which cover the whole life cycle of a building object. Table 1 presents the specification of opinions expressed by 156 experts who evaluated the importance of eight criteria applied to an assessment of a building investment in the whole life cycle. The data collated in the table 1, show a high degree of discrepancy at some of the criteria. In this situation, a frequent solution is to resort to weights applied to groups of experts. Table 2 shows the values connected with the preparation of data for further calculations. 


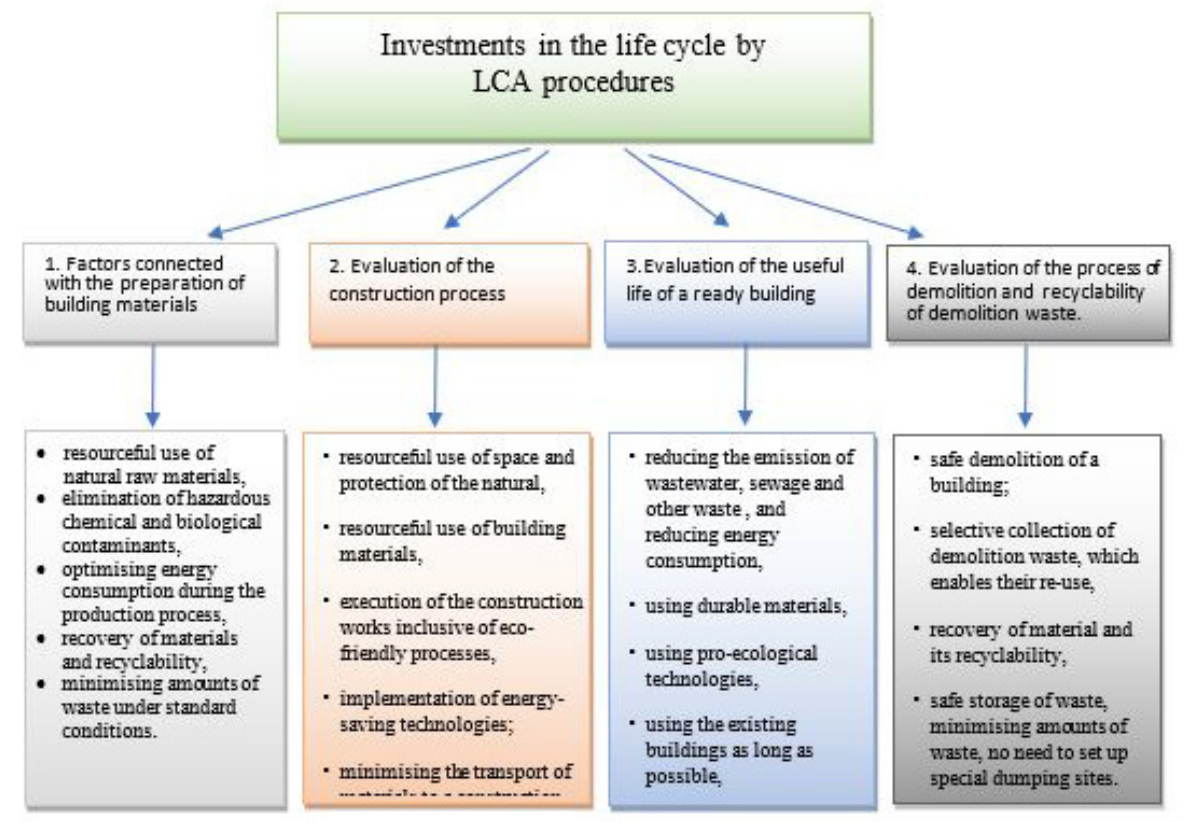

Figure 3. The hierarchical structure of chosen criteria for the AHP method

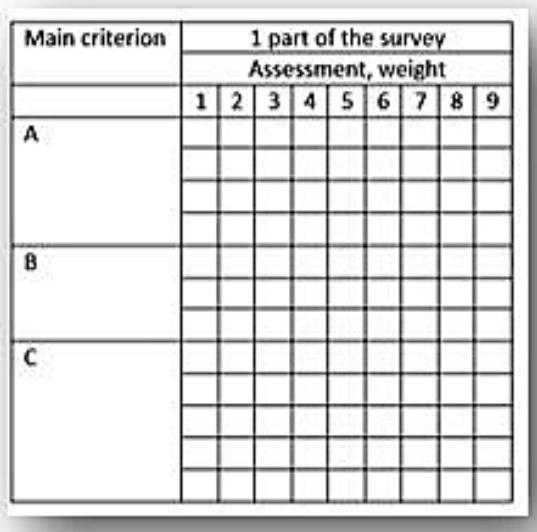

\begin{tabular}{|c|c|c|c|}
\hline \multirow[t]{2}{*}{ No. } & \multirow[t]{2}{*}{ Control questions } & \multicolumn{2}{|c|}{ Answer } \\
\hline & & Yes & No \\
\hline 1 & $\begin{array}{l}\text { Will there be a significant } \\
\text { change in the environment? }\end{array}$ & & \\
\hline 2 & $\begin{array}{l}\text { Will the impact be very } \\
\text { complex or unusual in } \\
\text { nature? }\end{array}$ & & \\
\hline 3 & $\begin{array}{l}\text { Will be covered by the } \\
\text { impact } \\
\text { an exceptionally wide area? }\end{array}$ & & \\
\hline 4 & $\begin{array}{l}\text { Will a large number of } \\
\text { natural components (fauna } \\
\text { and flora) be exposed to the } \\
\text { impact? }\end{array}$ & & \\
\hline 5 & $\begin{array}{l}\text { Will impact affect valuable } \\
\text { and scarce resources? }\end{array}$ & & \\
\hline
\end{tabular}

Figure 4. Examples of surveys prepared by the author of this research

Table 1. Summary of expert evaluations

\begin{tabular}{|c|c|c|c|c|c|c|c|c|}
\hline No. & Criteria / Evaluation & $\begin{array}{c}(0 p) \\
\text { Irrelevant }\end{array}$ & $\begin{array}{c}(1 p) \\
\text { Not important }\end{array}$ & $\begin{array}{l}(2 p) \\
\text { Valid }\end{array}$ & $\begin{array}{c}(3 p) \\
\text { Significant }\end{array}$ & \begin{tabular}{c|}
$(4 p)$ \\
Very important \\
\end{tabular} & $\begin{array}{c}5 p) \\
\text { Pivotal } \\
\end{array}$ & Sum \\
\hline & $\begin{array}{l}\text { Number of evaluation (for graphic } \\
\text { interpretation) }\end{array}$ & 1 & 2 & 3 & 4 & 5 & 6 & - \\
\hline 1 & Economical use of raw materials & 0 & 15 & 55 & 72 & 12 & 2 & 156 \\
\hline 2 & $\begin{array}{l}\text { The use of recycled } \\
\text { materials }\end{array}$ & 7 & 26 & 65 & 23 & 25 & 10 & 156 \\
\hline 3 & $\begin{array}{l}\text { Economical } \\
\text { use of the surface }\end{array}$ & 18 & 24 & 25 & 45 & 34 & 10 & 156 \\
\hline 4 & $\begin{array}{l}\text { The use of environmentally } \\
\text { friendly technologies }\end{array}$ & 0 & 0 & 28 & 37 & 41 & 50 & 156 \\
\hline 5 & $\begin{array}{l}\text { Limiting the consumption of } \\
\text { electricity and heat }\end{array}$ & 0 & 5 & 35 & 38 & 56 & 22 & 156 \\
\hline 6 & $\begin{array}{l}\text { The use of durable materials and } \\
\text { the longest possible use of the } \\
\text { object }\end{array}$ & 0 & 10 & 35 & 56 & 44 & 11 & 156 \\
\hline 7 & $\begin{array}{l}\text { Safe and easy demolition and } \\
\text { disassembly of the facility }\end{array}$ & 5 & 15 & 39 & 48 & 42 & 7 & 156 \\
\hline 8 & $\begin{array}{l}\text { The possibility of recycling used } \\
\text { materials }\end{array}$ & 2 & 29 & 29 & 45 & 46 & 5 & 156 \\
\hline
\end{tabular}


The replies obtained from the surveys show different characteristics. It is possible to observe the criteria for which there is one dominant answer (Fig. 5a), or else a distinct rising tendency (Fig. 5c). More details are presented in diagrams in Figure 5.

a) Distribution with a clear dominance of one answer (criterion 2)

b) Distribution with the dispersion of answers (criterion 3)

c) Distribution with a clear rising tendency (criterion 4)

d) Distribution having a shape of a classical gaussian curve (criterion 6)

The evaluations achieved in this way were subjected to a further procedure in order to calculate an average assessment. The last column in Table 2 shows the values of evaluations after normalisation - this is a vector of preferences showing weights of particular criteria. Their sum equals 1 .

Following the criteria above, it is now possible to identify the criteria which, according to experts' opinions, are more important. The fact that the experts assigned the least importance to the criteria connected with the preparatory actions, i.e. with the first stage of the life cycle of a building, is noteworthy.

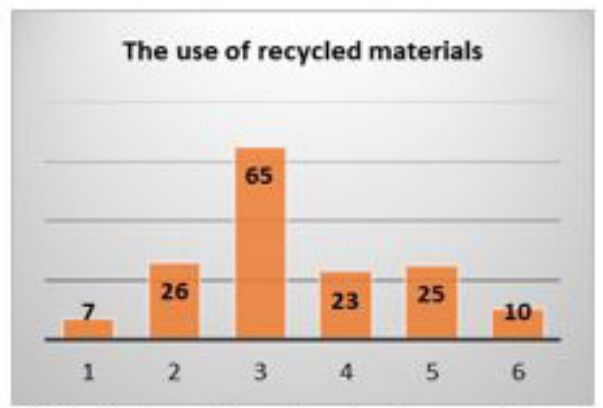

5 a) Distribution with a clear dominance of one answer (criterion 2)

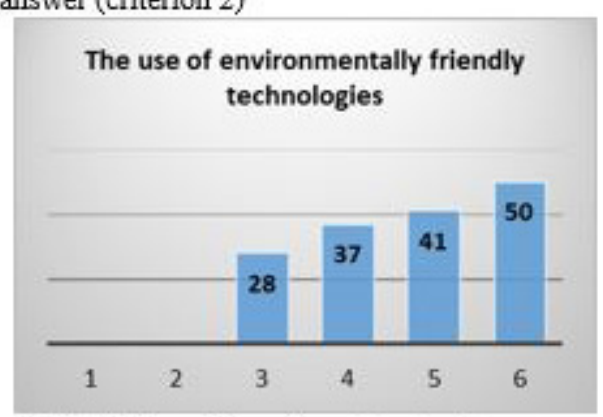

5 c) Distribution with a clear rising tendency (criterion 4)

\section{RESULTS}

The example presented above adheres to the provisions of the Polish and EU law, and contains a set of criteria to evaluate variant solutions of a planned building development which encompass the whole life cycle, from the preparation of materials to the demolition of the building. The analysis of data shows that the questions concerning the materials from recycled waste (criterion 2) and reduced consumption of energy (criterion 5) were met with the dominance of a single answer. This proves the high level of concordance between experts on these matters. A high degree of agreement was also reached with respect to the criterion of using eco-friendly technologies (criterion 4). Greater discrepancy was observed with respect to the answers which followed a Gaussian curve. These are the replies to the question about using durable materials (criterion 6), safe demolition (criterion 7) and economical use of raw materials (criterion 1). Much higher discrepancy and a certain information chaos arise from the answers acquired to the question about economical space management (criterion 3) and possible recycling of the demolition materials (criterion 8). This study showed that the responses varied

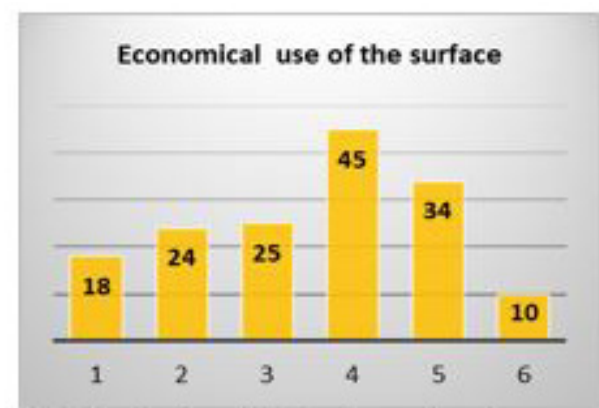

5 b) Distribution with the dispersion of answers (criterion 3)

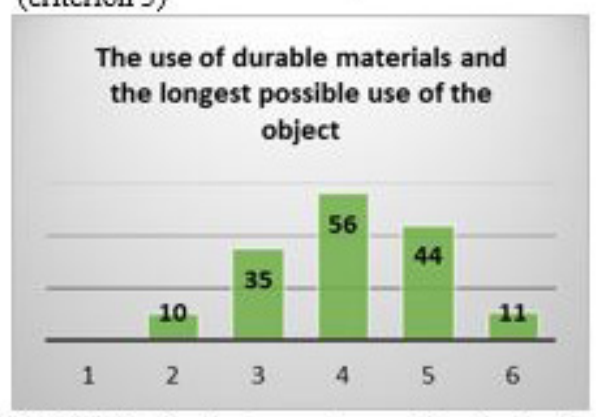

5d) Distribution having a shape of a classical gaussian curve (criterion 6)

Figure 5. Examples of distributions of answers in the analysed questionnaires 
Table 2. Calculation of the sum of assessments and vector of priorities through normalisation of results

\begin{tabular}{|c|c|c|c|c|c|}
\hline No. & Criteria/ Evaluation & $\begin{array}{c}\text { Number of } \\
\text { answers }\end{array}$ & $\begin{array}{c}\text { The sum of } \\
\text { ratings }\end{array}$ & Average points & $\begin{array}{c}\text { Evaluation after } \\
\text { normalization - weight }\end{array}$ \\
\hline 1 & $\begin{array}{l}\text { Economical use of raw } \\
\text { materials }\end{array}$ & 156 & 399 & 2,56 & 0,11 \\
\hline 2 & $\begin{array}{l}\text { The use of recycled } \\
\text { materials }\end{array}$ & 156 & 375 & 2,40 & 0,10 \\
\hline 3 & $\begin{array}{l}\text { Economical } \\
\text { use of the surface }\end{array}$ & 156 & 395 & 2,53 & 0,11 \\
\hline 4 & $\begin{array}{l}\text { The use of environmentally friendly } \\
\text { technologies }\end{array}$ & 156 & 581 & 3,72 & 0,16 \\
\hline 5 & $\begin{array}{l}\text { Limiting the consumption of electricity } \\
\text { and heat }\end{array}$ & 156 & 523 & 3,35 & 0,14 \\
\hline 6 & $\begin{array}{l}\text { The use of durable materials and the } \\
\text { longest possible use of the object }\end{array}$ & 156 & 479 & 3,07 & 0,13 \\
\hline 7 & $\begin{array}{l}\text { Safe and easy demolition and } \\
\text { disassembly of the facility }\end{array}$ & 156 & 440 & 2,82 & 0,12 \\
\hline \multirow[t]{2}{*}{8} & $\begin{array}{l}\text { The possibility of recycling used } \\
\text { materials }\end{array}$ & 156 & 431 & 2,76 & 0,12 \\
\hline & Sum & - & 3623 & 23,22 & 1,00 \\
\hline
\end{tabular}

depending on the type, functions and intended use of the analysed designs of planned buildings. Different answers were given depending whether residential buildings (housing estates) or industrial facilities were considered, and the replies given by experts enquired about planned road developments were completely unlike the previous ones.

This distribution of the replies is caused by experts somehow distancing themselves from the new group of questions connected with the durability of buildings, economical use of materials or space. The new approach is included in the regulations and EU directives, which mandate the inclusion of such criteria. They are gradually being added to the assessments of variant solutions of building development, and - with time - experts are becoming more inclined to adopt the complex approach to the pro-environmental design of variants of building investments.

The list of criteria which govern the final assessment output, presented in this article, proves their great diversity. A large number of criteria suggests that they would be difficult to compare directly. In order to apply a mathematical instrument such as e.g. a multicriterial analysis, it is necessary to order the parameters considered, and to create matrices of main criteria and subcriteria (Fig. 3).

The proposed procedure for analysing the environmental impact of construction investments, taking into account the life cycle of the object, is presented in Figure 6.

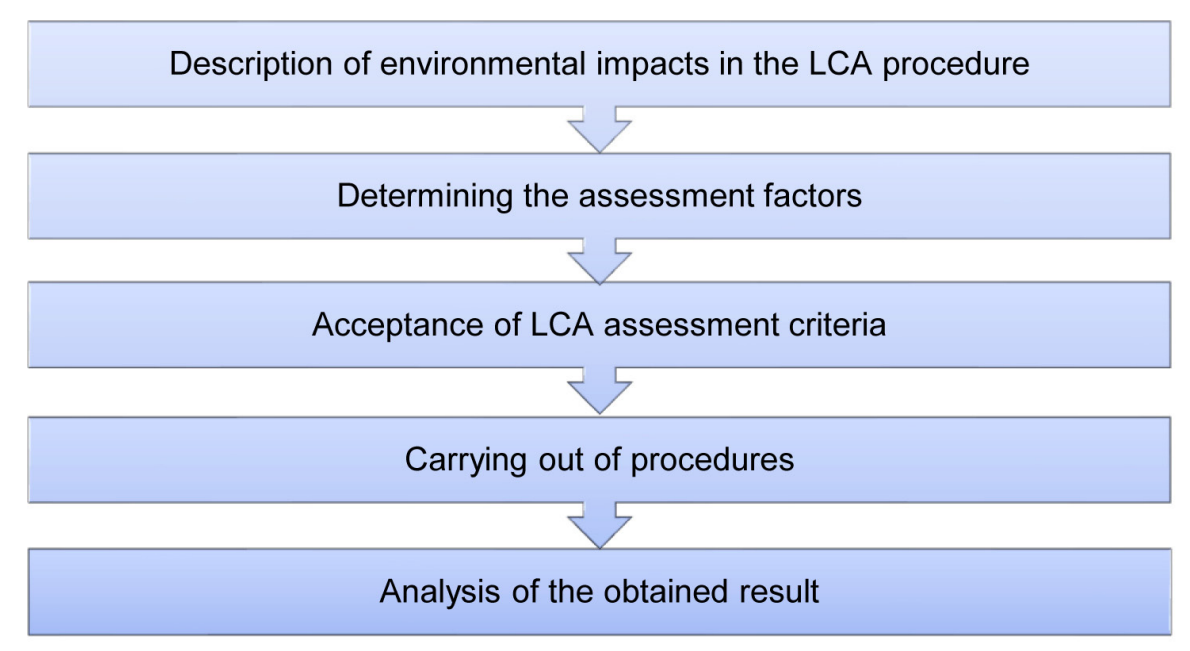

Figure 6. Scheme of a procedure according to the described procedure 


\section{CONCLUSIONS}

For centuries, the economic activities carried out by the man have posed numerous threats to nature. Some of the losses suffered thus far cannot be replaced. The implementation of new technologies and the development of systems which will enable us to evaluate the impact of new buildings on nature reflect the care we take about our surroundings. This article shows how many factors decide whether the man's activity in the field of civil engineering can be friendly to the environment or not. A complex approach to the assessment of an impact on the natural environment caused by various building objects allows us to take into account all stages in the building's life cycle. The research based on experts' opinions has provided evidence that there is not a single, universal set of criteria, and an appropriate set of criteria needs to be defined in each case.

The results presented in this paper are just a fragment of a larger study, and they are limited to the specific problems arising while making an assessment of the impact on the natural environment by building objects throughout their entire life cycle.

\section{REFERENCES}

1. Bribián, I. Z., Capilla, A. V., \& Usón, A. A. (2011). Life cycle assessment of building materials: Comparative analysis of energy and environmental impacts and evaluation of the eco-efficiency improvement potential. Building and environment, 46(5), 1133-1140.

2. Brown M. A. 2012. Construction management: the management of the development, conservation and improvement of the built environment. Organization, Technology \& Management in Construction: An International Journal, 4(2), 457-460.
3. Cabeza, L. F., Rincón, L., Vilariño, V., Pérez, G., \& Castell, A. (2014). Life cycle assessment (LCA) and life cycle energy analysis (LCEA) of buildings and the building sector: A review. Renewable and sustainable energy reviews, 29, 394-416.

4. Isaac S., Navon R. 2008. Feasibility study of an automated tool for identifying the implications of changes in construction projects. Journal of Construction Engineering and Management, 134(2), 139-145.

5. Marques G., Gourc D., Lauras M. 2011. Multicriteria performance analysis for decision making in Project Management. International Journal of Project Management, 929(8), 1057-106.

6. Mora, E. P. 2007. Life cycle, sustainability and the transcendent quality of building materials. Building and Environment, 3(42), 1329-1334.

7. Negahban S., Baecher G.B., Skibniewski M.J. 2012. A decision- making model for adoption of enterprise resource planning tools by small -to medium size construction organizations. Journal of Civil Engineering and Management, 8(2), 253-264.

8. Ortiz O., Francesc C., Sonnemann G. 2009. Sustainability in the construction industry: A review of recent developments based on LCA. Construction and Building Materials 23.1, 28-39.

9. Rodriguez-Pose A., Fratesi U. 2009. Between development and social policies: the impact of $\mathrm{Eu}-$ ropean Structural Funds in Objective 1 regions. Regional Studies, 38(1), 97-113.

10. Shen L. Y., Tam V. W., Tam L., Ji Y. B. 2010. Project feasibility study: the key to successful implementation of sustainable and socially responsible construction management practice. Journal of Cleaner Production, 18(3), 254-259.

11. Szafranko E., (2017). Application of multi-criterial analytical methods for ranking environmental criteria in an assessment of a development project. Journal of Ecological Engineering, 18(5), 151-159.

12. Szafranko, E. (2016). Evaluation of data obtained from expert opinions in multi-criteria analyses of construction investment variants. Archives of Civil Engineering, 62(2), 205-216. 